\title{
Microseismicity within a karstified rock mass due to cracks and collapses as a tool for risk management
}

\author{
L. Lenti $\cdot$ S. Martino $\cdot$ A. Paciello $\cdot$ A. Prestininzi $\cdot$ S. Rivellino
}

Received: 19 March 2010/Accepted: 1 June 2012/Published online: 17 June 2012

(C) The Author(s) 2012. This article is published with open access at Springerlink.com

\begin{abstract}
Seismometer arrays have been widely applied to record collapse by controlled explosion in mines and caves. However, most underground failures are natural events, and because they can occur abruptly, underground failures represent a serious geological hazard. An accelerometric array installed on 4 September 2008 has been used to manage the geological risk of the Peschiera Springs drainage plant of Rome's aqueduct, which is located in the Central Apennines approximately $80 \mathrm{~km}$ from Rome, Italy. The plant occupies a karstified carbonatic slope that is extensively involved in gravitational deformations, which are responsible for underground failures such as cracks and collapses. To distinguish among different types of recorded events, an automated procedure was implemented based on the duration, peak of ground acceleration (PGA) and PGA variation in the recordings of the plant's accelerometric stations. The frequencies of earthquakes and micro-earthquakes due to underground failures are, in general, well correlated. Nevertheless, many underground failure sequences can be directly associated with the continuous deformations that affect the slope. The cumulative Arias intensity trend derived for the underground failures combined with the failure and earthquake frequencies enabled the definition of a control index (CI) that identifies alarming or emergency conditions. The CI can be used as a tool for managing the geological risk associated with the deformational processes that affect the drainage plant.
\end{abstract}

L. Lenti

French Institute for Sciences and Technology for Transport, Development and Networks (IFSTTAR), Paris East University, 58 Boulevard Lefebvre, 75732 Paris Cedex 15, France

S. Martino $\cdot$ A. Prestininzi $\cdot$ S. Rivellino

Dipartimento di Scienze della Terra e Centro di Ricerca Previsione, Prevenzione e Controllo dei Rischi Geologici (CE.RI.), Università di Roma "Sapienza”, P.za U. Pilozzi 9, Valmontone, Rome, Italy

S. Martino $(\square)$

P.za A. Moro 5, 00185 Rome, Italy

e-mail: salvatore.martino@uniroma1.it

A. Paciello

Agenzia Nazionale per le Nuove Tecnologie, 1`Energia e lo Sviluppo Economico Sostenibile (ENEAC.R. Casaccia), Via Anguillarese 301, S. Maria di Galeria, 00060 Rome, Italy 
Keywords Microseismicity monitoring - Underground failures - Karstified rock mass · Geological risk

\section{Introduction}

Changes in stress conditions in rock masses due to impulsive and viscous deformations can cause rapid and violent failures that widely affect slopes and generate landslides or hypogeous collapses (Evans et al. 2006). The recognition of pre-failure events by geological surveys and monitoring of natural and anthropogenic systems is an important mean to mitigate the risks due to abrupt geological failures.

The pre-failure behaviour of rock masses represents a complex geomechanical problem because the stress and jointing conditions as well as the joint setting can strongly constrain pre-failure effects, such as crack generation, the opening or closing of joints and the readjustment of the stress field in the rock mass. All of these failure precursors can be monitored by specific devices. However, ongoing geological and geomechanical deformation, which can proceed from a transitional phase to rock-mass failure at yielding conditions, is indicative of the proneness of a rock mass to further deformation or failure (Szwedzicki 2003).

When the events related to failures are monitored, the transitional phase towards ultimate equilibrium represents a useful opportunity to observe the process that leads to failure. This type of monitoring can indicate the best management procedure to avoid losses and reduce damages before an emergency occurs.

Complex scenarios of failure involving rock masses can be associated with impulsive triggers (i.e. explosions or collapses) or earthquakes. In these cases, precursors do not necessarily occur, although possible triggers can be monitored. However, the observation of these triggering events is not sufficient for the mitigation of geological risks if the trigger intensity threshold and time delay of an induced rock-mass failure cannot be established.

Experiments have been performed in mines and landslide areas with the objective of monitoring failure precursors using acoustic and seismometric devices (Miller et al. 1989; Lei et al. 2004; Lai et al. 2006; Paskaleva et al. 2006; Deparis et al. 2008). However, hypogeous instabilities triggered by impulsive events were recorded during studies of collapse by the controlled explosion within mine areas (Phillips et al. 1997; Yang et al. 1998). Moreover, laboratory tests were performed on brittle materials to analyse possible correlations between acoustic emissions and observed microfracturing (Ganne et al. 2007) and to derive theoretical models of wave interaction with opened fractures in rocks to be applied in numerical modelling (Tang 1997; Eberhardt et al. 1998; Hildyard 2007).

Characteristic waveforms and frequency spectral features of microseismic emissions due to rock falls, collapses and explosions, both natural and artificially induced, have been collected and analysed by many authors (Miller et al. 1989; Phillips et al. 1997; Heng 2009; Walter et al. 2012). These studies demonstrated that only a specific comparison of signals generated by different events (i.e. natural events or natural and artificial ones) allows for a reliable discrimination.

The analysis of precursor sequences and post-failure events (i.e. underground instabilities induced by impulsive triggers) can be considered a useful tool for preventive intervention because monitoring of the phases of failure propagation provides information regarding the changes in the rock mass and the possible occurrence of more critical conditions (i.e. a generalised collapse). 
The monitoring of certain indicators, such as the displacement, stress, frequency of acoustic or microseismic emissions and the magnitude of the emitted signals, can help to distinguish trends that may be associated with decreasing, stationary and increasing hazards of failure, respectively, related to "regressive," "progressive" and "transgressive" sequences of instabilities according to Szwedzicki (2001, 2003).

For this study, a seismometric monitoring system was used to record underground failures that affect a gravitationally deforming karstified slope, on which the main drainage plant of Rome's aqueduct is located, and to derive a procedure for risk management at the plant, which consists of a complex system of drainage and collector tunnels and related connection halls. The analysis of the recorded earthquake and underground failure sequences has enabled the different events to be distinguished and characterised according to physical parameters. In addition, the analysis has provided interpretative criteria for the definition of different levels of alarm as a risk management tool for the drainage plant.

\section{The Peschiera Springs slope}

The Peschiera Springs slope corresponds to the south-western flanks of Mt. Nuria (Central Apennines, Italy; Fig. 1). The slope is composed of carbonate ridge and inner-platform limestones that belong to the Mt. Nuria unit (Capotorti et al. 1995; Ciotoli et al. 2001; Bigi and Costa Pisani 2002) and can be related to the Malm-Lower Cretaceous interval. The structural setting of the slope is monoclinic with EW-trending and $\mathrm{N}$-dipping $\left(30^{\circ}-40^{\circ}\right)$ strata. Many fault lines cross the slope with approximately NS and N35E trends (Figs. 2, 3).

The slope is located over a major karst aquifer, which represents the drainage system of the Nuria-Velino-western Fucino and western Marsica (Velino-Sirente) mountains (total surface area: $1,016 \mathrm{~km}^{2}$ ). The Peschiera-Canetra is the main group of Springs in this system (total measured discharge of approximately $18-21 \mathrm{~m}^{3} / \mathrm{s}$; Boni et al. 1986, 1995).

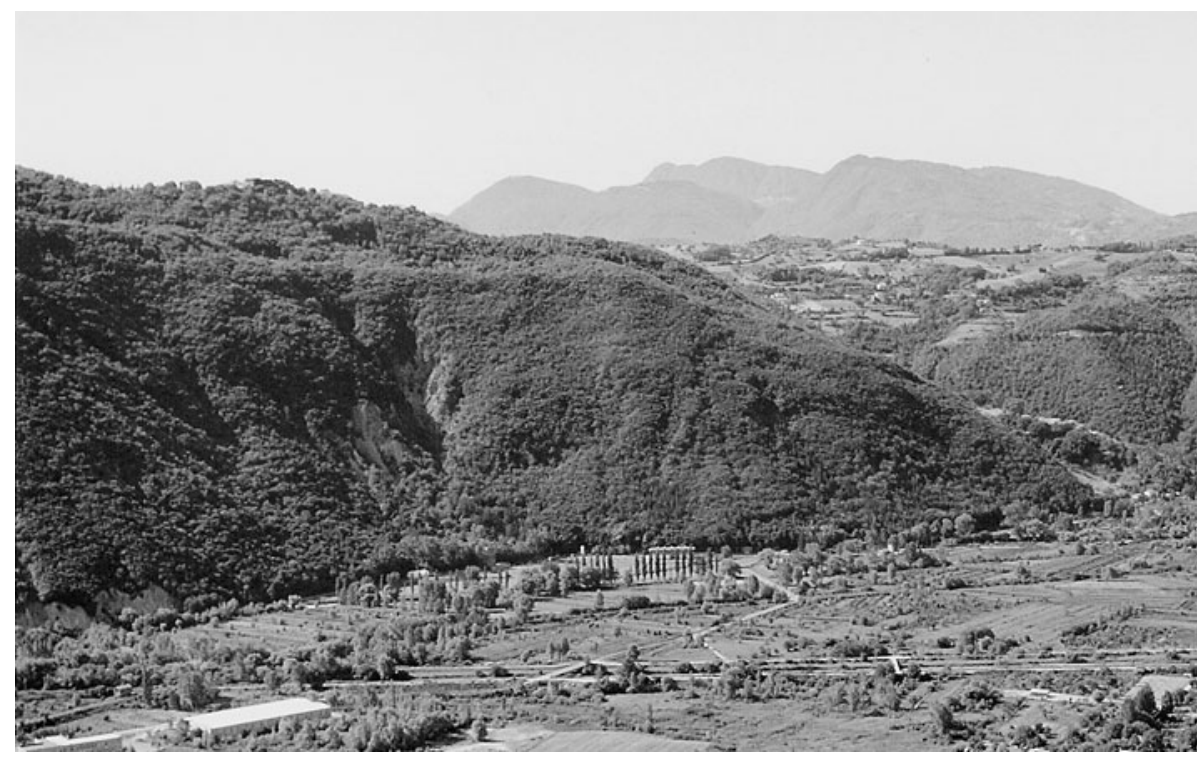

Fig. 1 Panoramic view of the Peschiera Springs slope from the S. Vittorino plain (Rieti, Italy) 

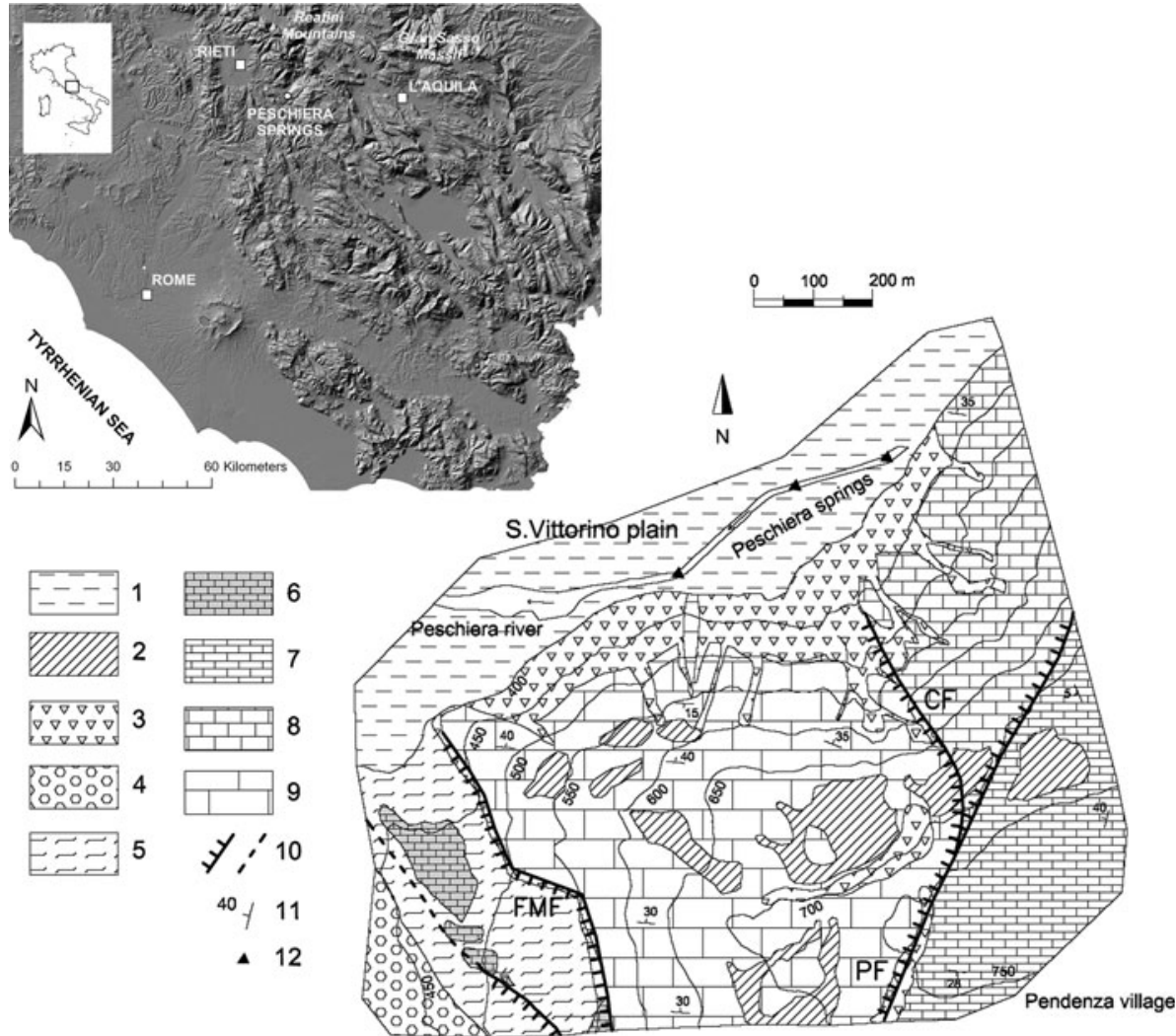

Fig. 2 Location and geological sketch of the Peschiera Springs slope: (1) Recent alluvial deposits of the Velino River; (2) Reddish soils; (3) Slope debris; (4) Gravel and conglomerate (upper-Pliocene and lowerPleistocene parts); (5) Sandy-clayey flysch (upper Miocene); (6) Marly limestone (upper Cretaceous-lower Miocene); (7) Birdseye micritic limestone (lower Cretaceous); (8) Coral limestone (upper Malm); (9) Coral and echinoids limestone (Malm part); (10) Fault (dashed if estimated): FMF Fiamignano-Micciani Fault, $C F$ Canalone Fault, $P F$ Pendenza Fault; (11) Strike and dip of strata; and (12) Springs

The Peschiera Springs drainage plant is part of the Rome aqueduct system managed by ACEA-ATO2 S.p.A., an Italian company.

Numerous gravity-induced morphological elements (e.g. scarps, trenches, sinkholes and tension cracks) were identified (Figs. 4, 5) using geomorphological surveys and a recent high-resolution $(2 \mathrm{~m}$ ) digital elevation model of the slope derived from a LIDAR (light detection and ranging) remote survey. These landforms are indicative of slow, intense and pervasive slope deformations that affect the entire slope. These deformations correspond to different evolutionary stages that are attributed to different portions of the slope, as demonstrated by data from a stress-strain monitoring system installed at the drainage plant (Martino et al. 2004; Maffei et al. 2005).

Many scarps (with a height varying from 5 to $15 \mathrm{~m}$ ) are present arranged both longitudinal and transverse to the slope (Figs. 4, 5). The majority of the steepest scarps are upslope at an elevation higher than $650 \mathrm{~m}$ a.s.l. and are mainly transversally arranged. Conversely, 5-10$\mathrm{m}$-high scarps are abundant in the mid-lower portion of the slope and have both longitudinal and transversal arrangements. Scarps with a height lower than $5 \mathrm{~m}$ typically border 

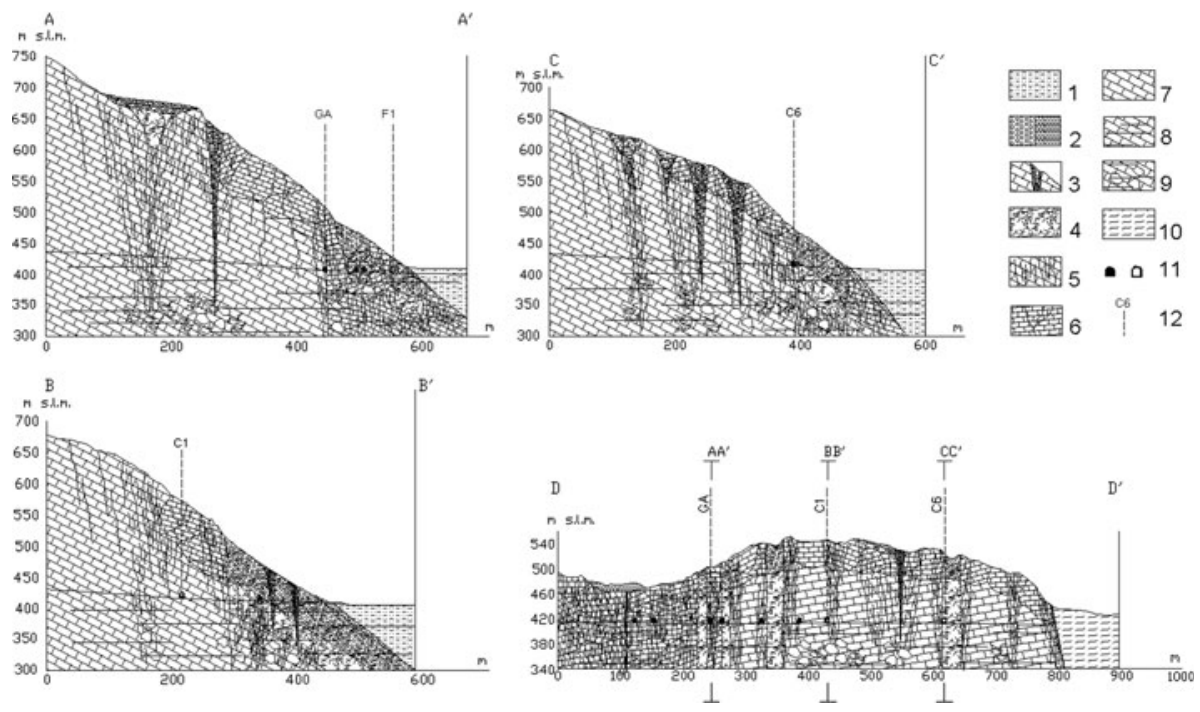

Fig. 3 Geological sections along traces $\mathrm{AA}^{\prime}, \mathrm{BB}^{\prime}, \mathrm{CC}^{\prime}$ and $\mathrm{DD}^{\prime}$ of Fig. 4: (1) Alluvial deposits of the S. Vittorino plain; (2) Trench and slope debris (left and right, respectively); (3) Sinkhole; (4) Intensely jointed rock mass; (5) Concentration of cracks in the rock mass; (6) Dislodged rock mass; (7) Rock mass located above the water table; (8) Rock mass located in the karst aquifer; (9) Underground caves in the karst aquifer; (10) Flysch; (11) Drainage plant tunnel; and (12) Location of the accelerometric station

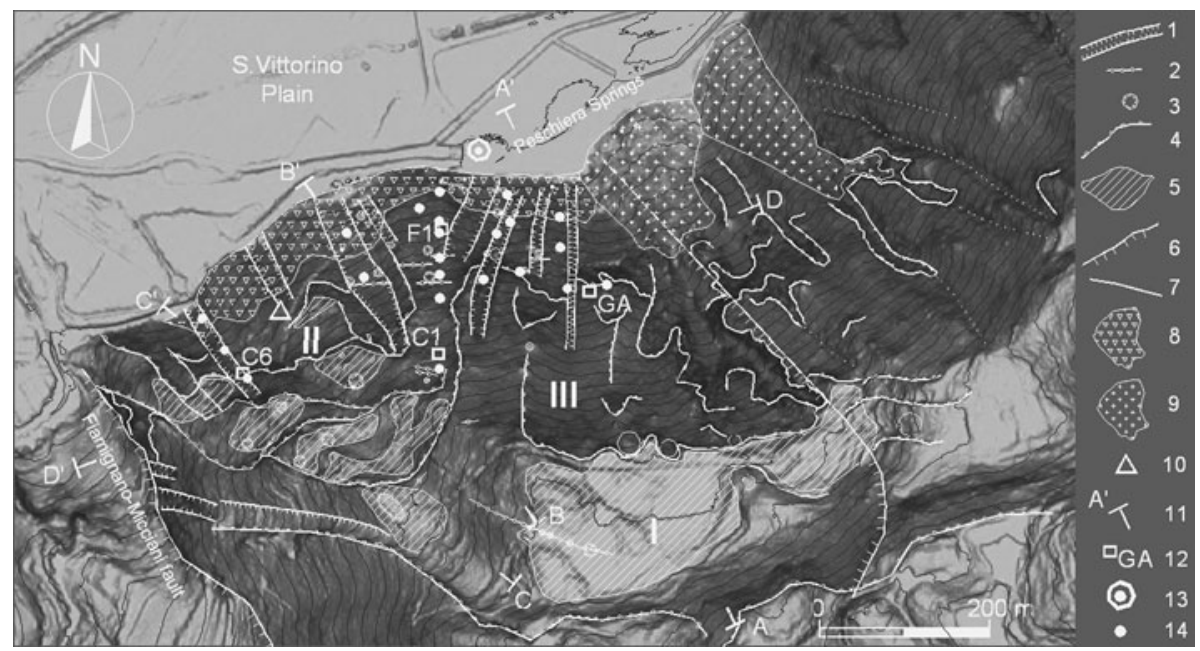

Fig. 4 Digital elevation model (DEM) based on the LIDAR remote survey showing geomorphological features; the traces of the geological sections of Fig. 3 are also shown. (1) Trench; (2) Tension crack; (3) Sinkhole; (4) Scarp; (5) Karstified flat; (6) Fault; (7) Gully; (8) Slope debris; (9) Debris fan deposit; (10) Location of the rock fall of 22 March 2011 recorded by the accelerometric network at the plant; (11) Trace of the geological cross-sections (see Fig. 3); (12) Accelerometric station at the drainage plant; (13) Reference point for the azimuthal distribution of the time integral of the square velocity, derived from seismic noise records; (14) Velocimetric station for measuring seismic noise at the drainage plant. Slope sectors (I, II and III) at different evolutionary stages are also shown 

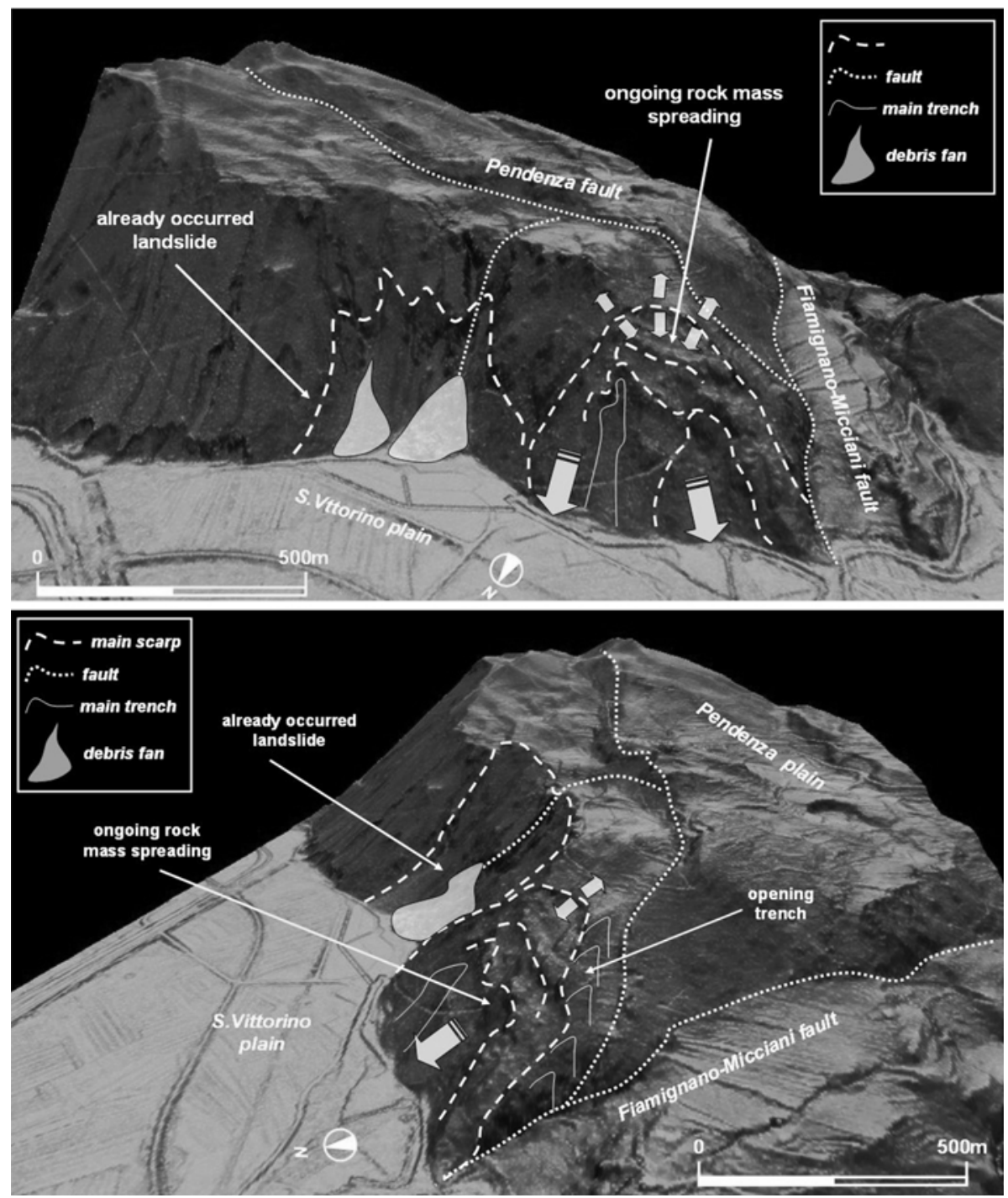

Fig. $53 \mathrm{D}$ views of the DEM of Fig. 4 showing the earlier landslide and the ongoing rock-mass spreading that affect the Peschiera Springs slope

longitudinal trenches, which are well represented below $600 \mathrm{~m}$ a.s.l. These scarps show evidence of recent movements locally. Trenches are generally filled with coarse and heterometric debris, which supplies a wide debris slope and occasional debris cones.

A number of sinkholes and depressions of variable sizes (diameter: $5 \mathrm{~m}$ to approximately $15 \mathrm{~m}$; depth: $0.5 \mathrm{~m}$ to approximately $9 \mathrm{~m}$ ) can be observed along the entire slope. Most of the sinkholes and depressions are downslope of the main transversal scarps or in the trenches, whereas other sinkholes and depressions are aligned along open tension cracks. Generally, non-circular forms are elongated approximately $\mathrm{N} 60 \mathrm{~W}$ or $\mathrm{N} 10 \mathrm{E} \pm 10$ and therefore are approximately parallel to the prevailing directions of the tension cracks and trenches. 
Diffuse evidence of tension cracks can be observed. These tension cracks produce openings in the exposed bedrock, which generally occur without fill, or narrow and elongated depressions, that contain smaller depressions and sinkholes in the sectors having a thicker debris cover or residual reddish soils. The tension cracks may reflect new scarps or the retreat of prior scarps.

The geomorphological evidence enabled the recognition of three slope sectors (Fig. 3) with ongoing gravity-induced processes at different evolutionary stages (Martino et al. 2004): (1) a sector that includes the southern and top portions of the slope with evidence of incipient but limited deformation (sector I of Fig. 4); (2) a western sector with a mature but not yet advanced evolution of gravity-induced deformations, where the major deformations are concentrated near the most marked gravity-induced elements (sector II of Fig. 4); and (3) an eastern sector with an advanced evolution characterised by pervasive deformation and pronounced gravity-induced elements, such as scarps, trenches and sinkholes (sector III of Fig. 4). In this last sector, block-sized debris that fills a large channel may have originated from the collapse of one portion of the slope as a result of terminal-stage deformations.

The geological-evolutionary model of the slope reflects a complex deep-seated gravitational deformation, which initiates a "sackung" phenomenon (Zischinsky 1969; Savage and Varnes 1987) that continuously evolves from rock-mass spreading (Hutchinson 1988) to rock-block mass deformation (Martino et al. 2004). In particular, rock-mass spreading can be clearly observed in the western portion of the slope, which shows a radial displacement field and is causing transversal scarps and longitudinal trenches (i.e. multiple transversal trenches; Figs. 4, 5).

The initial evolutionary stage of rock-mass deformation is mainly controlled by primary anisotropies and the morphology of the relief. This deformation generates subvertical belts of tensile stress that gradually produce tension cracks and multiple transversal trenches.

The spreading is associated with the collapse of underground caves due to major karst dissolution within the relieved rock mass, that is, along the subvertical belts (Maffei et al. 2005; Casini et al. 2006). These collapses result in a loss of volume at the surface, which results in depressions and sinkholes. This process dislodges large rock blocks from the volumes bounded by the multiple transversal trenches. The dislodged blocks are highly mobile, which increases the jointing of the rock mass, that is, the number of cracks per unit volume. The resulting mechanism can be regarded as rock-block mass deformation.

Additionally, the collapse of underground caves may be triggered by external stressors, such as earthquakes (Maffei et al. 2005). On 11 October 1997, a sinkhole collapse was caused by an event of the Umbria-Marche seismic sequence (maximum magnitude $M_{w}=6.05$ ). The episode involved one of the slope's deepest sinkholes (depth: $9 \mathrm{~m}$; max diameter: $15 \mathrm{~m}$; min diameter: $10 \mathrm{~m}$ ), and the coarse debris from the sinkhole plugged part of the local drainage pipeline (length: approximately $20 \mathrm{~m}$; depth: approximately $75 \mathrm{~m}$ below the surface). This event demonstrates the spatial continuity between sinkholes and caves inside the slope. The evolutionary stages described above can be recognised as moving from the western towards the eastern portion of the slope, as shown in Figs. 3 and 5, and along sections $\mathrm{AA}^{\prime}, \mathrm{BB}^{\prime}$ and $\mathrm{CC}^{\prime}$ of Fig. 3 when viewed from east to west along the Peschiera Springs slope.

\section{Accelerometric monitoring system}

\subsection{Accelerometric data}

Beginning on 4 September 2008, four accelerometric stations (GA, C1, F1 and C6 of Fig. 3) were installed at the Peschiera Springs drainage plant to record seismic events and 
underground failures, that is, events due to collapses and rock-mass cracking. The accelerometric network, owned by ACEA-ATO2 S.p.A., is managed by the Research Centre for Geological Risk (CERI) of the Sapienza University of Rome in co-operation with the Italian National Agency for New Technologies, Energy and Sustainable Economic Development ENEA - Rome, Italy) and the French Institute for Sciences and Technology for Transport, Development and Networks (IFSTTAR-Paris, France). Each station was equipped with a triaxial accelerometer (KINEMETRICS EPISENSOR) directly installed on the bedrock. The four accelerometers were connected via cables to a 12-channel digital data logger (K2 KINEMETRICS) set to the absolute local time using a GPS device with a $250 \mathrm{~Hz}$ sampling frequency.

The trigger criteria of the data logger were set to record events characterised by different durations and large-band frequency content. To this end, station $\mathrm{C} 1$ was set in the STA/LTA (short-time amplitude/long-time amplitude) trigger mode, which is devoted to the detection of low-magnitude earthquakes. The other stations were set with a threshold trigger fixed according to the local noise level. Two different types of band-pass filters from the KINEMETRICS library, "classic strong motion" (CSM) with a band-pass of approximately $1-10 \mathrm{~Hz}$ and "IIR B" with a band-pass of approximately $1-20 \mathrm{~Hz}$, were applied to the channels of the recording stations. One channel of stations GA, F1 and C6 uses a CSM filter, whereas the remaining 9 channels use an IIR B filter. Only two channels out of twelve are required to trigger the network.

Preliminary seismic noise measurements were performed at 22 stations at the Peschiera Springs drainage plant (Fig. 4) to select the locations for the accelerometric stations and determine the optimal trigger parameters for the network. The moving noise station was equipped with three triaxially arranged $1 \mathrm{~Hz}$ velocimeters (SS1 KINEMETRICS) connected to a 24 bit and $130 \mathrm{~dB}$ digital data logger (K2 KINEMETRICS).

The noise was recorded for approximately $20 \mathrm{~min}$ at a $250 \mathrm{~Hz}$ sampling frequency. The data were analysed in the frequency domain, that is, using fast Fourier transform (FFT), to derive the spectral content and related energy contributions computed as the time integral of the square velocity (TISV) over different frequency ranges and in different directions. The noise processing was performed by applying a band-pass filter in frequency windows of $1 \mathrm{~Hz}$ (from 0 to $15 \mathrm{~Hz}$ ) and $5 \mathrm{~Hz}$ (from 15 to $80 \mathrm{~Hz}$ ).

The results of this spectral analysis demonstrated the following: (1) in the $1-2 \mathrm{~Hz}$ frequency range, the energy contribution can be related to the water flow because the highest TISV values are observed along the direction parallel to the drainage channels; (2) in the $7-8 \mathrm{~Hz}$ frequency range, the energy contribution is nominally related to the frequency of the pump's engine (located outside the slope), and the energy contribution's effect is equal in the horizontal components; and (3) in the $45-50 \mathrm{~Hz}$ frequency range, the energy contribution includes the frequency of the alternating current, and higher spectral amplitudes are obtained for the horizontal component parallel to the electrical cables.

\subsection{Data processing and detection of events}

Until February 2012, approximately 1,200 events were recorded by the Peschiera Springs accelerometric network. These events were separated into earthquakes and micro-earthquakes, that is, cracks and collapses associated with underground failures (Fig. 6). To recognise the different types of events, the physical properties of the recorded waveforms were analysed in the time domain, and the PGA variation among the recording stations was considered (Fig. 7). For this purpose, a PGA-variation index (VI) percentage was defined in the following form: 


$$
\mathrm{VI}=\left(\left(\mathrm{PGA}_{\max }-\mathrm{PGA}_{\text {average }}\right) / \mathrm{PGA}_{\text {average }}\right) \times 100
$$

In the case of an earthquake, the VI value does not exceed $40 \%$, whereas in the case of a micro-earthquake, the value can reach $130 \%$ due to the higher seismic attenuation of local events, that is, events originated within the slope (Fig. 7b). Accordingly, earthquakes can be distinguished from micro-earthquakes using this index. Based on the local values of PGA due to records of earthquakes characterised by different $M_{w}$ (Fig. 7a), when VI $\leq 40$ (i.e. an earthquake), the PGA is used to recognise the following (Fig. 8): (a) near-field (epicentral distance $\leq 50 \mathrm{~km}$ ) high-magnitude events $\left(M_{w} \geq 5\right.$ ); (b) near-field (epicentral distance $\leq 50 \mathrm{~km}$ ) low-magnitude $\left(M_{w}<5\right)$ events; and (c) far-field (epicentral distance $>50 \mathrm{~km})$ high-magnitude $\left(M_{w} \geq 5\right)$ events. The magnitude $\left(M_{w}\right)$ and location of the earthquakes are defined by a real-time earthquake catalogue (http://cnt.rm.ingv.it/). For underground events (VI $>40 \%$ ), the duration can be used (Fig. 7c) to distinguish cracks from collapses because collapses have an average duration of approximately $0.1 \mathrm{~s}$, that is, two orders of magnitude shorter than the mean duration observed for cracks. These values
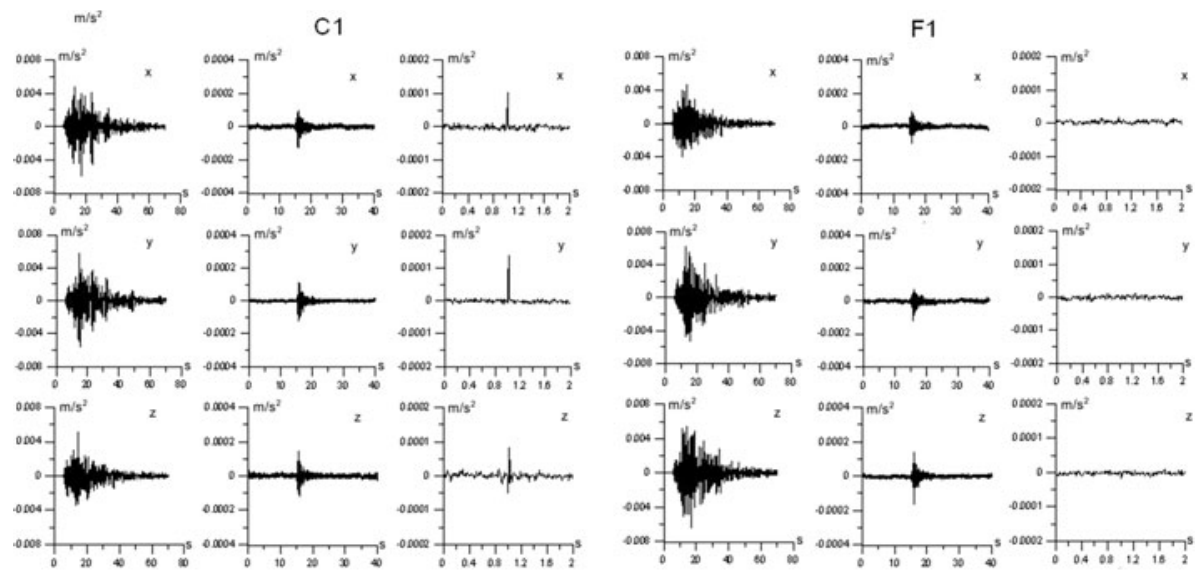

GA
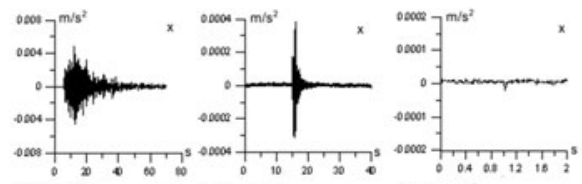

C6
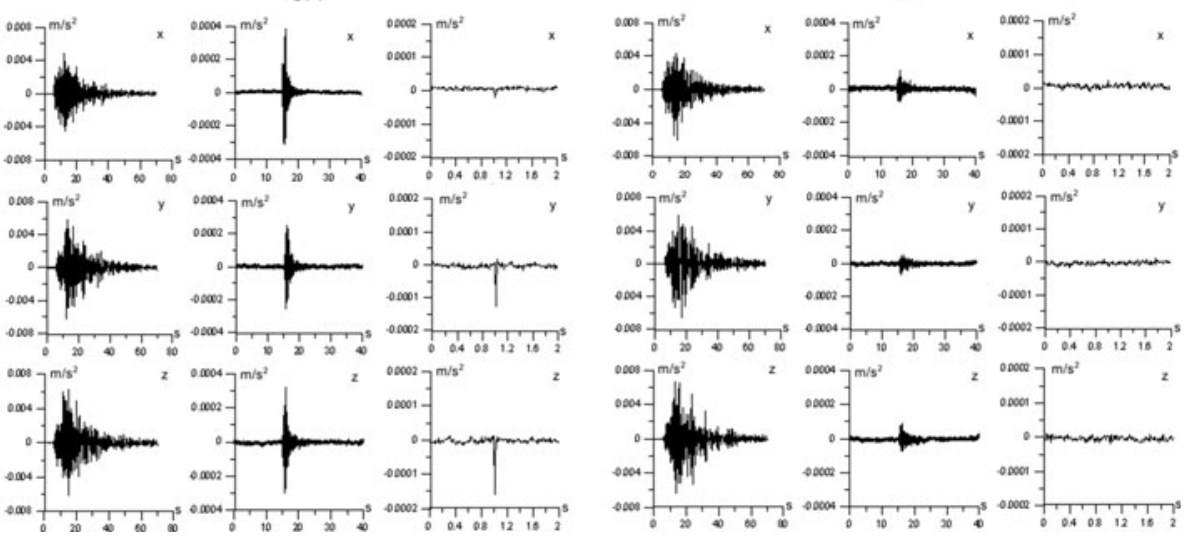

Fig. 6 Example of simultaneous records at the four accelerometric stations (GA, C1, F1 and C6) of the Peschiera Springs array. Records of the following events are shown for each station (from left to right) and each component of the motion ( $x, y, z$ from top to bottom): the 9 April 2009 earthquake (02:55:00; $\left.M_{w}=5.1\right)$, the 29 April 2009 crack (22:06:21) and the 4 July 2009 collapse (19:32:31) 

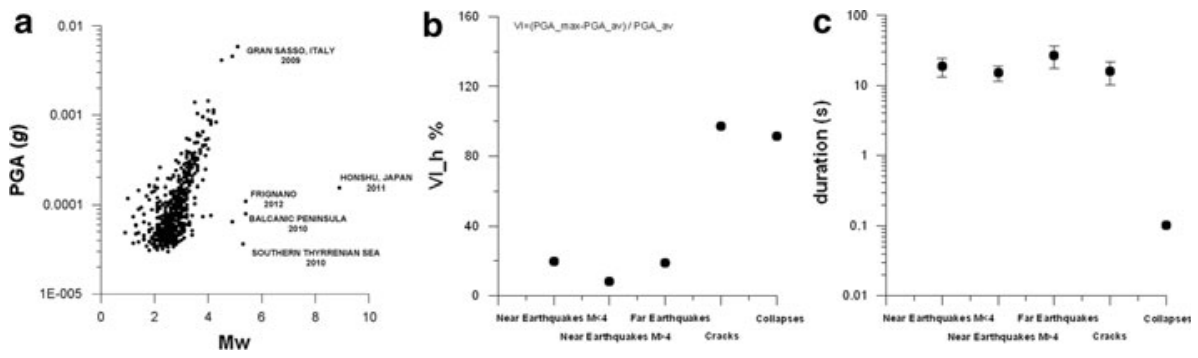

Fig. 7 a PGA versus $M_{w}$ obtained for the earthquakes recorded by the Peschiera Springs accelerometric network; b VI \% of the horizontal components with respect to the different event types detected by the Peschiera Springs accelerometric network (standard deviations are negligible); c durations and related standard deviations (error bars) corresponding to the different event types detected by the Peschiera Springs accelerometric network

are in good agreement with the results of other authors (Miller et al. 1989; Phillips et al. 1997; Yang et al. 1998; Paskaleva et al. 2006; Lai et al. 2006; Walter and Joswig 2008; Wust-Bloch and Joswig 2006; Walter et al. 2012) for waveforms associated with similar underground events.

To automatically detect the events recorded by the accelerometric network, a software application was implemented using Seismic Analysis Code (SAC) and Fortran on a Unix platform. The application classifies the events based on the values of the previously mentioned parameters and corresponding thresholds (Fig. 8).

To consider the possibility of automatically detecting the recognised events directly based on the accelerometric records, a spectral analysis was performed using FFT (Fig. 9). No significant differences were noted between ambient noise and micro-earthquakes due to underground failures. Because the FFTs of the cracks might reveal differences at frequencies higher than $8 \mathrm{~Hz}$, a more sophisticated comparison of relative errors computed in the frequency domain between the noise and the crack events was performed. This analysis demonstrated an approximately $50 \%$ probability of distinguishing the cracks from the ambient noise by FFT of the signal for the signal's entire duration.

Subsequently, a different approach was attempted. Representative spectrograms of each type of recorded events (i.e. earthquakes, cracks and collapses) are shown in Fig. 10. The

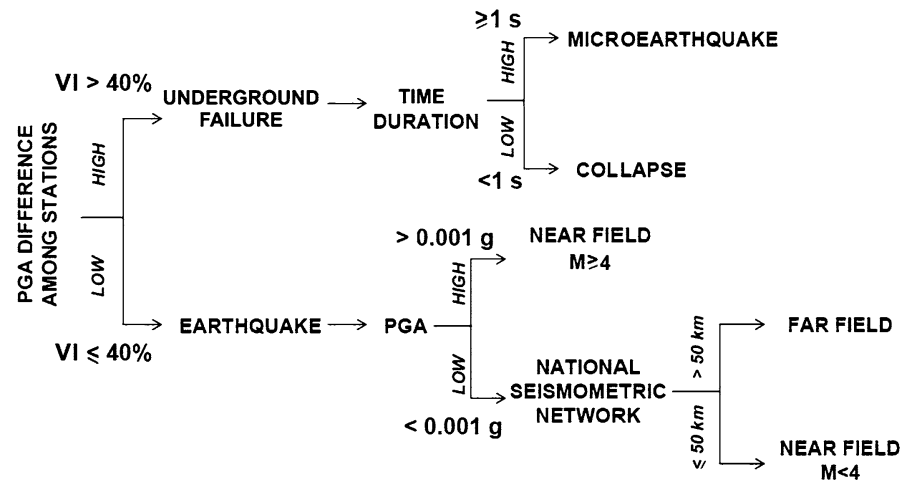

Fig. 8 Flowchart of the detection procedure used to distinguish the different event types recorded by the Peschiera Springs accelerometric network 
records were previously filtered in the range of $0.1-50 \mathrm{~Hz}$ (to enable the transfer functions of the accelerometric sensors to be held constant) using a 4-pole band-pass Butterworth filter. A sliding data window length of $1 \mathrm{~s}$ and a slice interval of $0.05 \mathrm{~s}$ were adopted to generate the spectrograms. In good agreement with Joswig (1990, 1994), the examples prove that spectrograms, as a type of "mental image," represent a powerful tool for detecting micro-earthquakes, which produce a distinctive visual pattern with respect to the ambient noise. In addition, the spectrograms can help to classify the seismic events. For example, Fig. 10 shows that the frequency content of a recorded earthquake is limited to approximately $10 \mathrm{~Hz}$, whereas the recorded micro-earthquakes, that is, from cracks and collapses, are characterised by significant frequency content up to $50 \mathrm{~Hz}$.

The recorded seismic signals were analysed according to their PGA values (Fig. 11). The maximum PGA related to the collapses (approximately $1.3 \times 10^{-3} \mathrm{~g}$ ) was observed at station $\mathrm{C} 1$ on the vertical component, whereas the maximum PGA for cracks (approximately $2.5 \times 10^{-4} \mathrm{~g}$ ) was obtained at station GA on the horizontal component. A similar analysis, based on the average Arias intensity, revealed that this parameter does not exceed $6 \times 10^{-9} \mathrm{~g}^{2} \mathrm{~s}$ (vertical component at station $\mathrm{C} 1$ ) for underground failures (i.e. collapses and cracks).

Additionally, the distribution of the maximum observed PGA as a function of the recording station as well as the motion components was taken into account (Fig. 12). At station $\mathrm{C} 1$, approximately $70 \%$ of the recorded collapses show the maximum PGA value on the motion's vertical component. The remaining $30 \%$ show the maximum PGA at station GA (Fig. 12a). However, approximately $90 \%$ of the recorded cracks show the maximum PGA at station GA, which in this case is not associated with a specific component of the motion (Fig. 12b).

These results indicate that the micro-earthquakes related to cracks and collapses generally originate in the slope's eastern portion, where stations GA and $\mathrm{C} 1$ are located. The evidence presented here is in good agreement with the evolutionary model of the gravityinduced deformation that affects the slope, which indicates that the eastern sector (stations $\mathrm{C} 1$ and GA) is involved in more intense and diffuse deformations and is characterised by an intensely jointed rock mass (Martino et al. 2004; Maffei et al. 2005).

\subsection{Sequences of recorded events}

As a further analysis, the time distribution of the detected earthquakes and micro-earthquakes enables the recognition of sequences (Fig. 11) based on the anomalous frequency
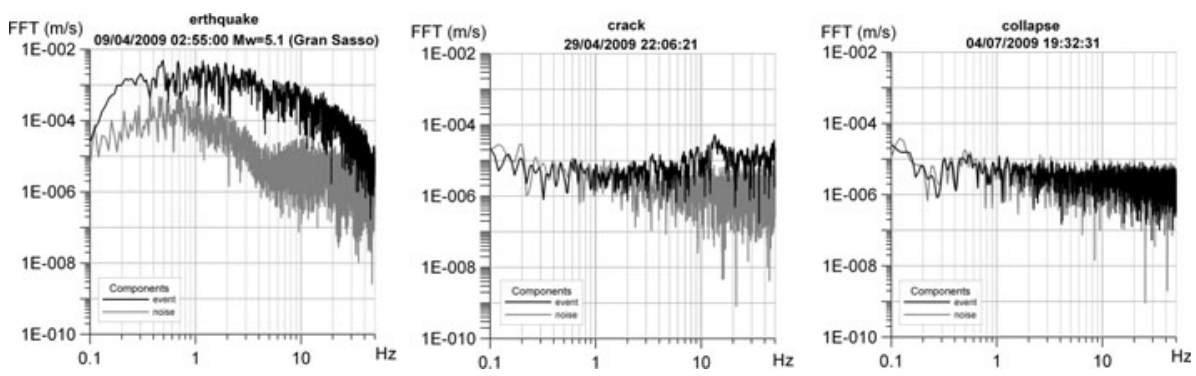

Fig. 9 Example comparisons of the FFT of each event type (i.e. earthquake, crack and collapse) recorded by the Peschiera Springs accelerometric network as well as the FFT of the simultaneous seismic noise; significant differences can only be observed for earthquakes 

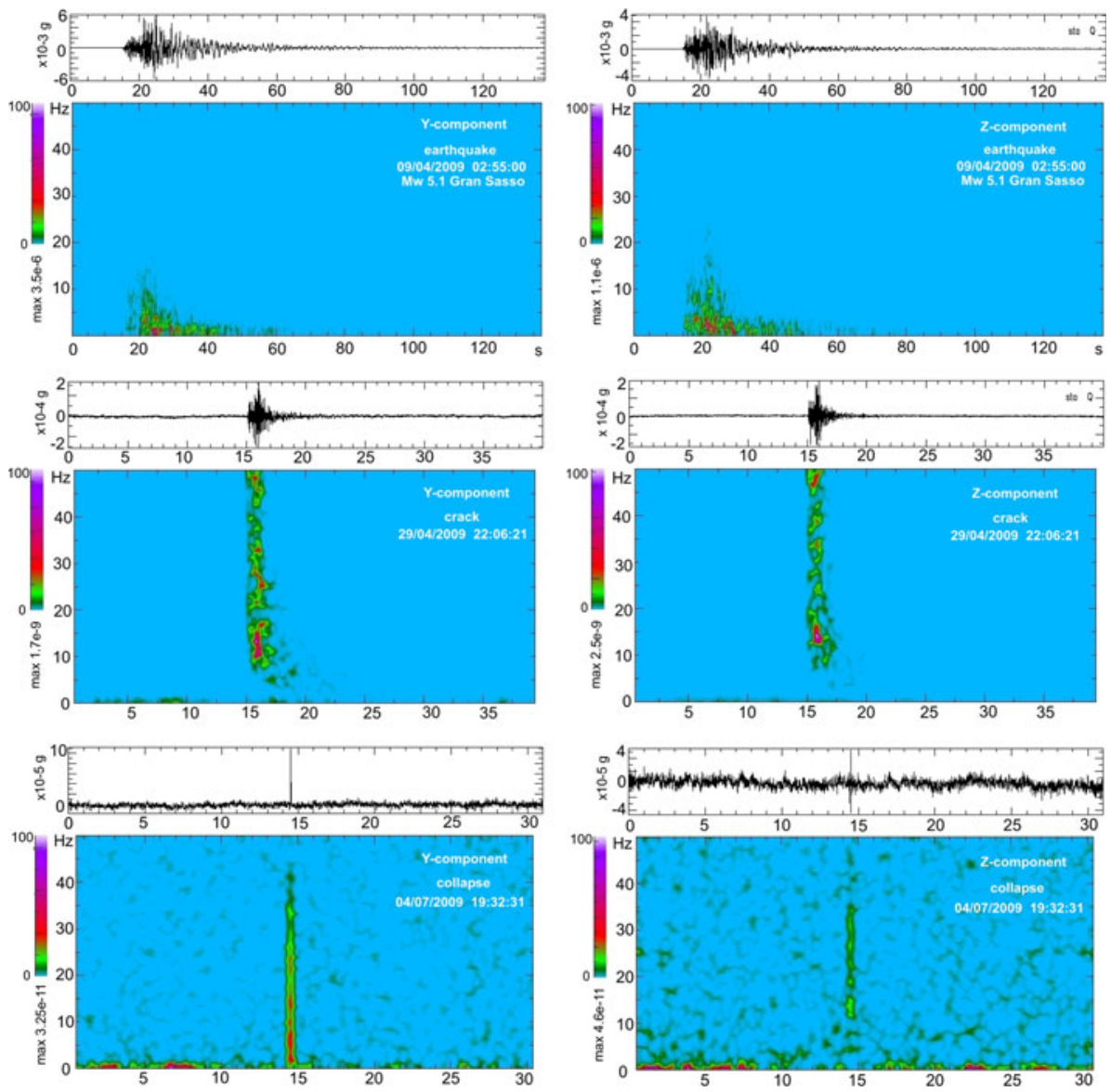

Fig. 10 Example spectrograms obtained for the horizontal (y) and vertical ( $z$ ) components of the ground motion for each event type (i.e. earthquake, crack and collapse) recorded by the Peschiera Springs accelerometric network

of the events (i.e. more than 10 events per day for earthquakes and more than 3 events per day for micro-earthquakes) as follows:

(a) the L'Aquila sequence, which started on 28 March 2009 and reached $M_{w}=6.3$ on 6 April 2009 at 3:32 a.m. (it is worth noticing that this main shock was not recorded, since the hard-disk memory of the data logger was full because of the numerous earthquakes recorded during the previous night hours);

(b) the Valle dell'Aterno-Gran Sasso-Monti della Laga sequence, which started on 9 April 2009 and ended in June 2009 with the $M_{w}=5.1$ main shock;

(c) the Reatini mountains sequence, 25 June 2009 to July 2009, which was characterised by intermediate-to-low-magnitude earthquakes (i.e. up to $M_{w}=4.0$ );

(d) a micro-earthquake sequence due to cracks, 22 December 2009 to the beginning of January 2010. This sequence was characterised by 9 cracks with PGA values between $10^{-3}$ and $10^{-4} \mathrm{~g}$; 

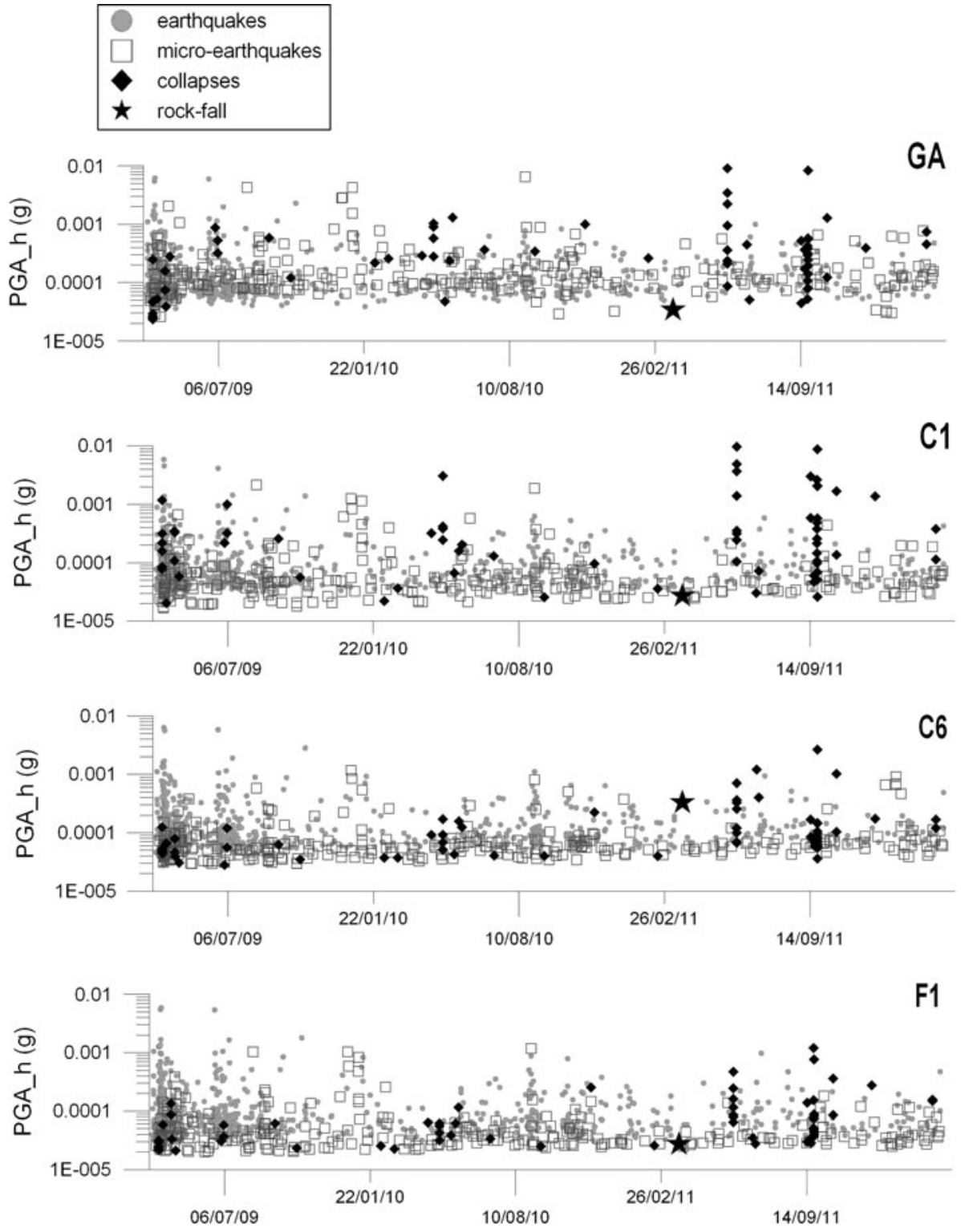

Fig. 11 Earthquake and micro-earthquake sequences caused by underground instability events recorded at the accelerometric stations on the Peschiera Springs slope from 28 March 2009 to 22 February 2012. The average values of the horizontal PGA components (PGA_h) are plotted for each accelerometric station

(e) a micro-earthquake sequence due to collapses concentrated on 27 April 2010 with 4 events within a few minutes and a maximum PGA value of $5 \times 10^{-3} \mathrm{~g}$ followed by three further events until 23 May 2010 with minor intensity;

(f) the Reatini mountains sequence, 11 August 2010 to the end of October 2010, with approximately 40 events of $M_{w} 2-3.6$; 

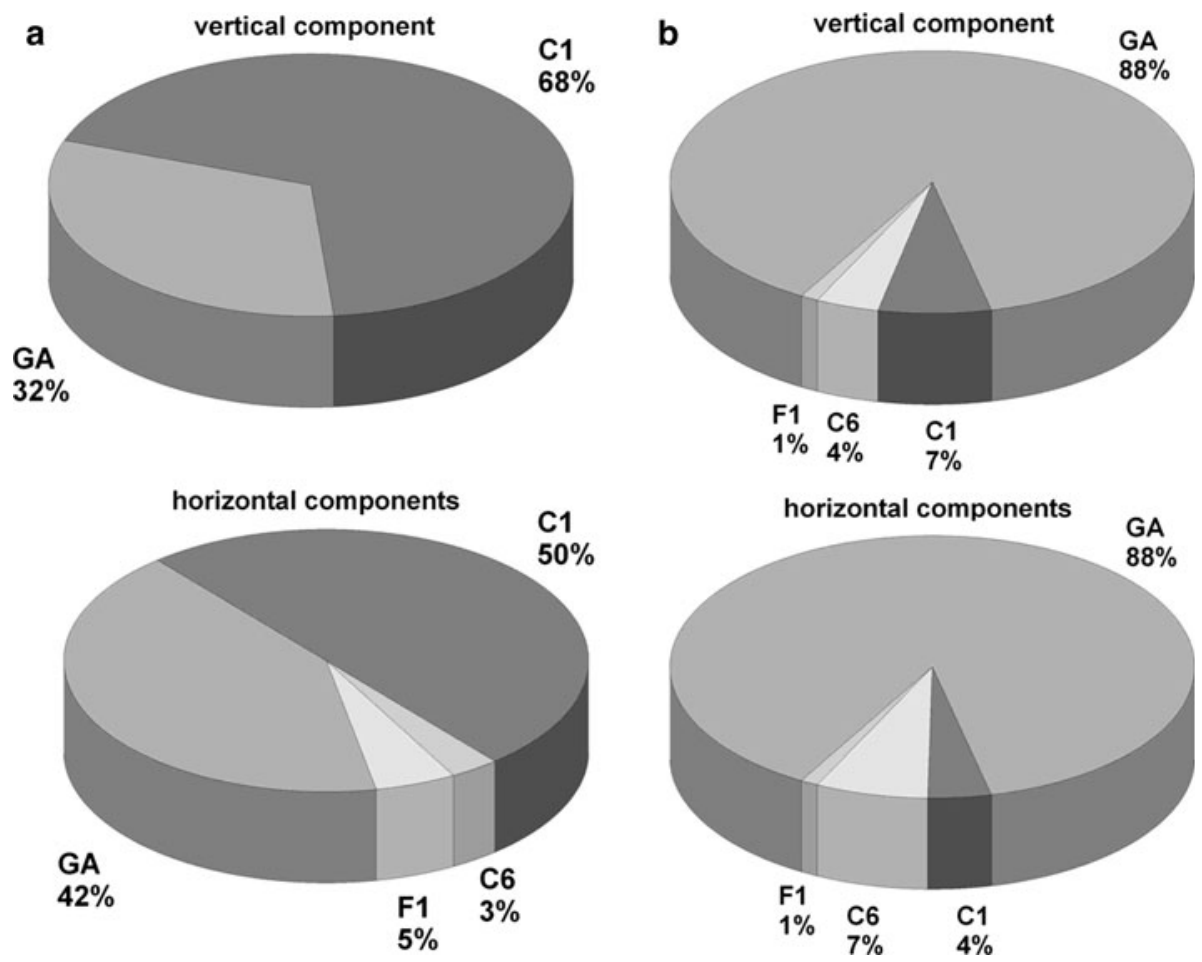

Fig. 12 Percentage distribution of the maximum PGA values (for each ground motion component) of the collapse (a) and crack (b) events recorded at the four stations of the Peschiera Springs accelerometric network (see Fig. 4 for location)

(g) a micro-earthquake sequence due to 8 collapses that occurred within 8 min on 5 June 2011 and which reached a maximum PGA of $2 \times 10^{-2} \mathrm{~g}$;

(h) a micro-earthquake sequence due to 15 collapses that occurred within approximately half an hour on 23 September 2011 with a maximum PGA of $2 \times 10^{-2} \mathrm{~g}$.

Although their start times differ, the first two listed sequences evolved contemporaneously, and a significant decrease in seismic activity was observed starting 23 July 2009. The PGA values of the recorded earthquakes with an epicentral distance of 30-50 km and an $M_{w}$ of 1.8-5.1 vary in the range of $3 \times 10^{-5}-6 \times 10^{-3} \mathrm{~g}$ (Fig. 6a). The frequency of occurrence (Fig. 11) of the seismic events computed for 1/3 day shows a sharp decrease in recorded seismicity within 2 weeks of the main shock of the L'Aquila sequence, from 37 events to 2 events per $1 / 3$ day, followed by an increase to 7 events per $1 / 3$ day during the Reatini mountains sequence. Moreover, during these seismic sequences, approximately 80 micro-earthquakes related to underground failures were recorded with PGAs up to approximately $2 \times 10^{-3} \mathrm{~g}$.

The micro-earthquake sequences that occurred in April of 2010 and June and September of 2011 consisted of a total of 27 collapses with a PGA up to $2 \times 10^{-2} \mathrm{~g}$. In these periods, seismic sequences did not occurred, and only a limited number of near-field earthquakes of $M_{w}<4$ were recorded by the network. 
The Reatini mountains seismic sequence of August to October of 2010 was characterised by a maximum earthquake frequency of 2 events for 1/3 day. In addition, during the sequence, 26 micro-earthquakes related to underground cracks were recorded.

During the entire duration of the network's operation, only one rock-fall event of approximately $100 \mathrm{~m}^{3}$ occurred (22 March 2011) from a scarp located on the slope surface (Fig. 13) whose location is reported in Fig. 4 and is close to station C6. This event was recorded at the plant with a maximum PGA of $3 \times 10^{-4} \mathrm{~g}$ at station C6 (Fig. 11).

\section{Alert system}

The analysis of the recorded events demonstrated that, in general, the frequencies of the seismic sequences and the underground failures are strongly correlated. However, many underground failures can be associated with the continuous slope deformations. In this regard, the underground failures recorded during April to May of 2010 were not related to any seismic event or sequence. The failures occurred several weeks before the Reatini mountains sequence of September 2010.

This evidence is in good agreement with the ongoing gravity-induced deformations on the slope, which cause underground instabilities independent of external action.

The event record is a useful tool for managing the natural risk due to underground failures at the Peschiera Springs drainage plant. For this purpose, the frequencies of the earthquakes and underground failures as well as the cumulative Arias intensity of the underground failures were plotted as a function of time (Fig. 14).

The resulting graphs suggest that different increment trends can be derived from the cumulative Arias intensity. For example, an increasing-rate trend was observed during the 5 days following the L'Aquila main shock (i.e. until 10 April 2009), a constant-rate trend was observed during the following 3 weeks (i.e. until 30 April 2009) and a decreasing-rate trend was observed in the following period (i.e. until the end of August 2009). Linear correlations were obtained for the logarithm of the cumulative Arias intensity versus time in the aforementioned time intervals. These correlations correspond to angular coefficients that decrease by one order of magnitude per time interval down to $2 \times 10^{-3}$. These results are in good agreement with certain indicators, such as the displacement, stress, frequency of acoustic or micro-seismic emissions and magnitude of the emitted signals that were used by other authors (Szwedzicki 2001, 2003) to distinguish trends associated with a decreasing, stationary and increasing failure hazard, which could be named "regressive," "progressive" and "transgressive," respectively.

To provide an alarm system for the plant in the case of underground events, a frequency index $\left(\mathrm{FI}_{(P, t)}\right)$ was defined as the sum of an earthquake frequency index $\left(\mathrm{FI}_{-} \mathrm{er}_{(P, t)}\right)$ and a micro-earthquake frequency index $\left(\mathrm{FI}_{-} \mathrm{me}_{(P, t)}\right)$ (Fig. 15; Table 1). These daily indexes are assigned to each station based on frequency classes defined according to the inventory of the daily frequency of the recorded events. Moreover, based on the previously described rate of cumulative Arias intensity of the recorded micro-earthquakes, a daily energy index $\left(\mathrm{EI}_{(P, t)}\right)$ (Fig. 15; Table 2) is attributed to each station. Additionally, in this case, the index is based on classes of values defined according to the cumulative Arias intensity rates measured at the plant.

A final control index $\left(\mathrm{CI}_{(P, t)}\right)$, which is a function of the sum of the frequency and energy indexes $\left(\mathrm{FI}_{(P, t)}+\mathrm{EI}_{(P, t)}\right)$, was defined. The $\mathrm{CI}_{(P, t)}$ is computed daily for each station in the network. The resulting values enable the association of each specific plant sector (represented by the corresponding accelerometric station) with three possible levels of 
Fig. 13 Photograph of the rockfall landslide of 22 March 2011 on the Peschiera Springs slope and related spectrograms of the three ground motion components recorded at station $\mathrm{C} 6$ of the accelerometric network
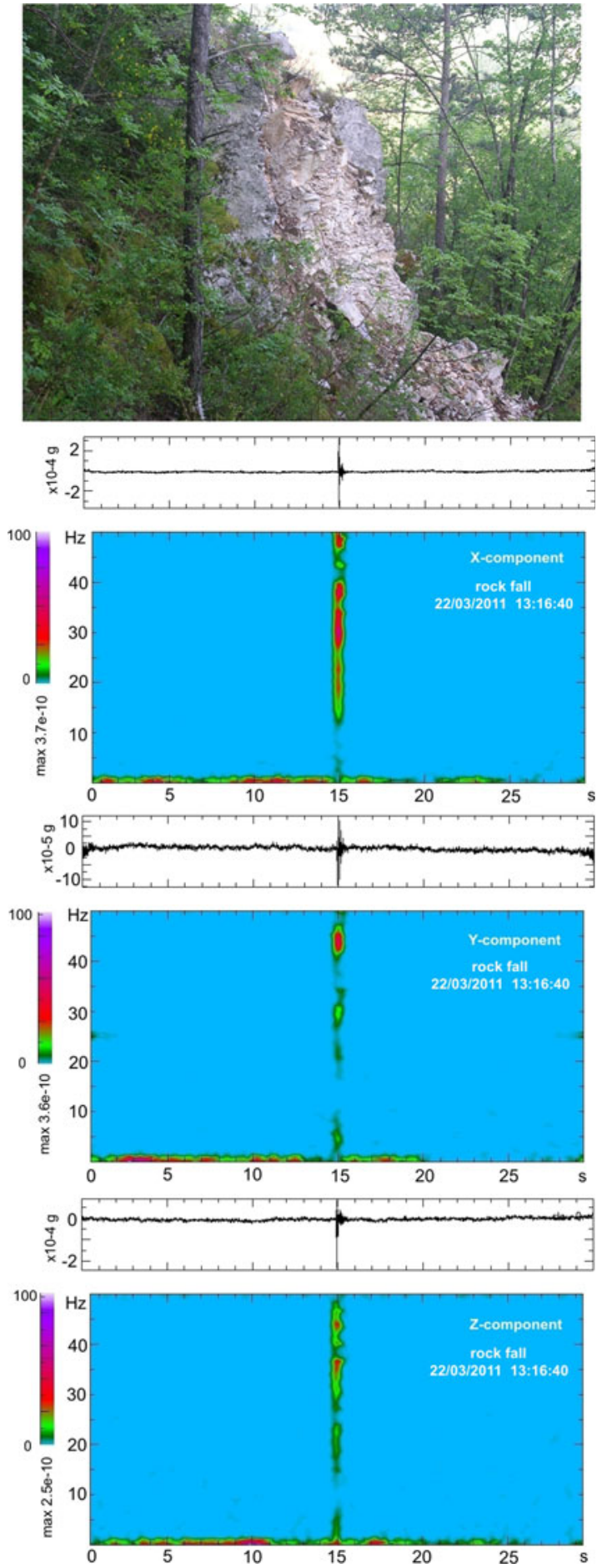
Fig. 14 Distribution of the following parameters within the time interval 28 March 2009 to 22 February 2012: a earthquake frequency per $1 / 3$ day; $\mathbf{b}$ microearthquake frequency per 1/3 day; c Arias intensity of the micro-earthquakes; and $\mathbf{d}$ the control index (CI) for each accelerometric station

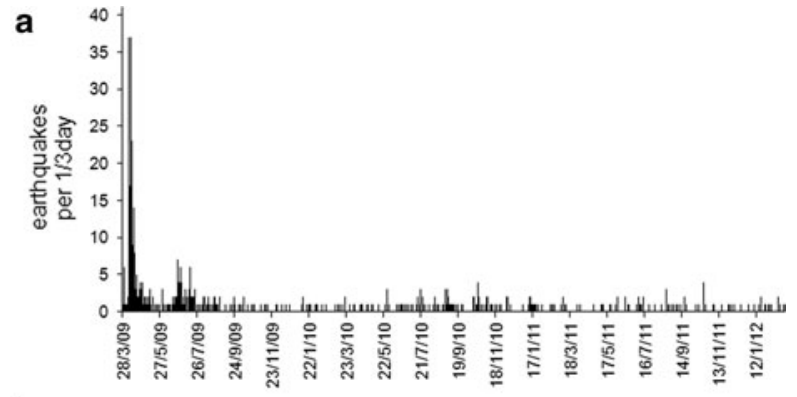

b

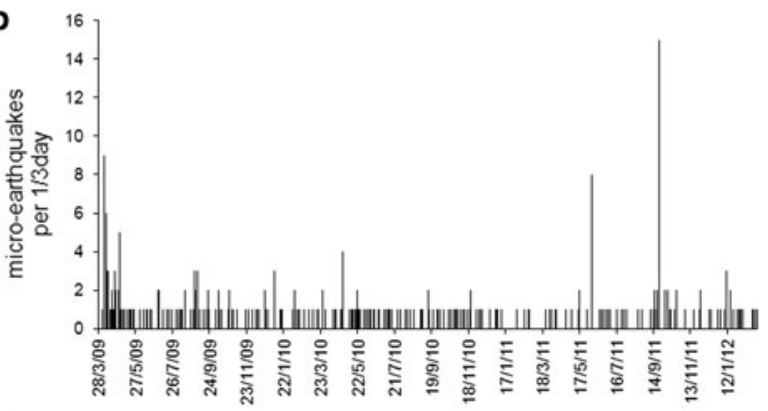$$
\text { 音 }
$$

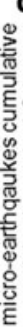
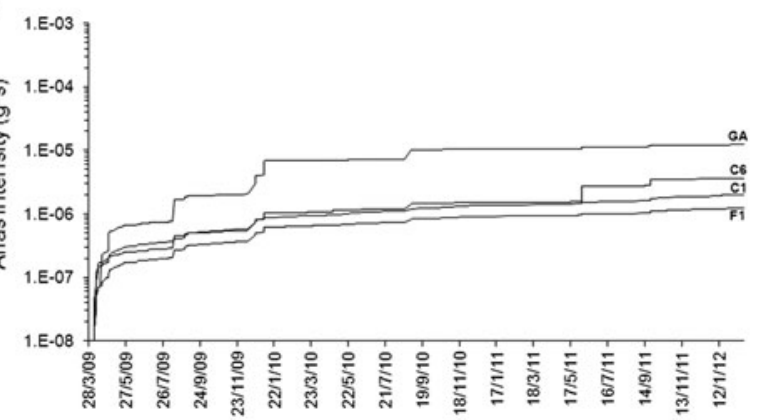

d
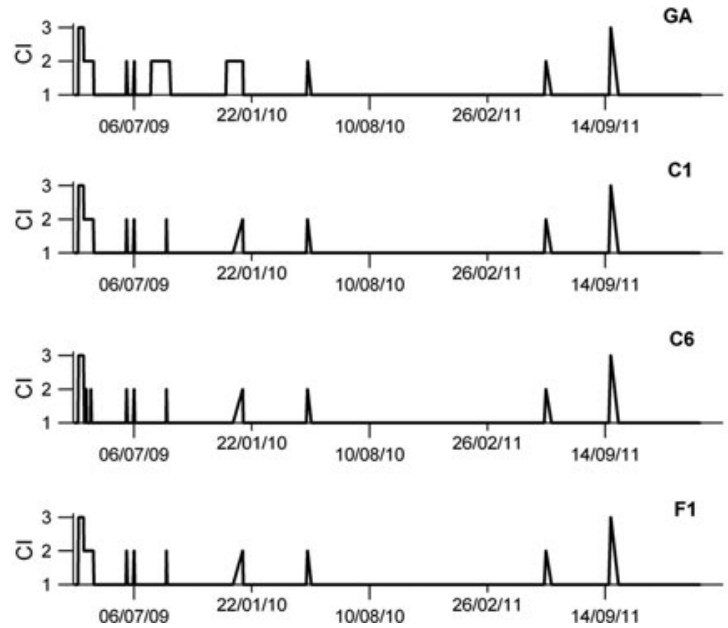


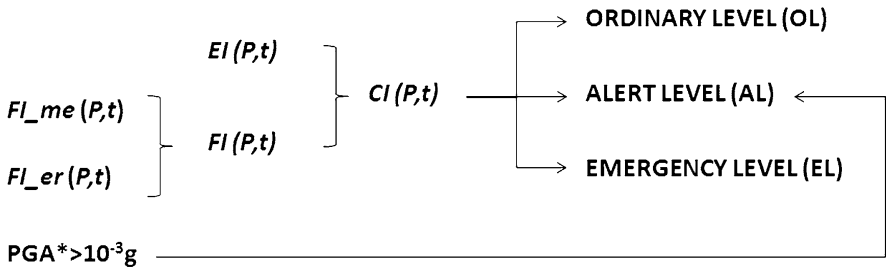

* micro-earthquakes or earthquakes

Fig. 15 Flowchart of the proposed drainage plant alarm system for underground failures with daily displayed levels of attention (i.e. ordinary, alert and emergency)

Table 1 Frequency index values $\left(\mathrm{FI}_{(P, t)}\right)$, computed by adding the earthquake frequency index $\left(\right.$ FI_er $\left._{(P, t)}\right)$ and the micro-earthquake frequency index $\left(\mathrm{FI} \_\mathrm{me}_{(P, t)}\right)$

Table 2 Cumulative Arias intensity rate values of the recorded micro-earthquakes used to define the energy index $\left(\mathrm{EI}_{(P, t)}\right)$

Table 3 Control index values $\left(\mathrm{CI}_{(P, t)}\right)$ corresponding to the three levels of attention

The $\mathrm{CI}_{(P, t)}$ values were computed by adding the $\mathrm{FI}_{(P, t)}$ and $\mathrm{EI}_{(P, t)}$ indexes of Tables 1 and 2

\begin{tabular}{lll}
\hline $\begin{array}{l}\text { Earthquake frequency } \\
\text { (event/day) }\end{array}$ & $\begin{array}{l}\text { Micro-earthquake } \\
\text { frequency (event/day) }\end{array}$ & FI_er/me $(P, t)$ \\
\hline $0-10$ & $0-3$ & 0 \\
$11-20$ & $4-10$ & 1 \\
$>20$ & $>10$ & 4 \\
\hline
\end{tabular}

\begin{tabular}{lc}
\hline Energy rate $\left(\mathrm{g}^{2}\right)$ & $\mathrm{EI}_{(P, t)}$ \\
\hline$\leq 10^{-3}$ & 0 \\
$10^{-3} / 10^{-2}$ & 1 \\
$>10^{-2}$ & 4 \\
\hline
\end{tabular}

\begin{tabular}{lll}
\hline Alarm level & $\mathrm{FI}_{(P, t)}+\mathrm{EI}_{(P, t)}$ & $\mathrm{CI}_{(P, t)}$ \\
\hline Ordinary & 0 & 1 \\
Alert & $1-3$ & 2 \\
Emergency & $4-12$ & 3 \\
\hline
\end{tabular}

attention: the "ordinary" level $(\mathrm{OL})\left(\mathrm{CI}_{(P, t)}=1\right)$; the "alert" level $(\mathrm{AL})\left(\mathrm{CI}_{(P, t)}=2\right)$; and the "emergency" level (EL) $\left(\mathrm{CI}_{(P, t)}=3\right)$ (Table 3$)$. To take into account additional individual events of significant intensity, an alert threshold was fixed at a PGA value of $10^{-3} \mathrm{~g}$, which corresponds to the value that is expected to be exceeded during near-field earthquakes with $M_{w}>5$ based on the local PGA-magnitude curve derived thus far (Fig. 7a).

\section{Conclusions}

The gravity-induced deformations involving the Peschiera Springs slope (Central Italy), where Rome's aqueduct drainage plant is located, cause underground instabilities that 
affect the rock mass. Over approximately 3 years (September 2008 to February 2012), an accelerometric array installed at the drainage plant recorded approximately 900 earthquakes and approximately 350 micro-earthquakes. The micro-earthquakes can be referred to as underground cracks and collapses.

A physical analysis of the seismic records performed by SAC-Fortran software enabled the recognition of different types of events, such as earthquakes, collapses and cracks, in terms of characteristic parameters, that is, PGA, duration and magnitude. A statistical analysis of the spatial distribution of the recorded micro-earthquakes demonstrated that the micro-earthquakes are directly related to the deformational processes that affect the slope. The cracks and collapses mainly occur in the slope's eastern portion, where intense deformations affect the intensely jointed and released rock-mass bands, and a high concentration of underground caves can be expected.

Many underground failure sequences can be directly attributed to the continuous slope deformation because triggering seismic events were not recorded by the accelerometric array. Nevertheless, near-field seismic sequences (i.e. sequences characterised by epicentral distances $\leq 50 \mathrm{~km}$ ) with $M_{w}>4$ and underground failures are generally strongly correlated, as observed during the 2009 L'Aquila seismic sequence and the June-July 2009 and August-October 2010 Reatini mountains seismic sequences.

Based on the analysis of the recorded sequences of earthquakes and micro-earthquakes, an alert strategy was developed for the Peschiera Springs drainage plant. The strategy consists of associating a level of attention (ordinary, alert and emergency) with different plant sectors, each represented by an accelerometric station. These levels of attention are attributed according to the control index $\mathrm{CI}_{(P, t)}$ derived from the daily frequency of the events recorded at each station and the rate of cumulative Arias intensity of the micro-earthquakes associated with the underground failures. The levels of attention determine different procedures to manage the geological risk to the plant due to underground failures.

\section{Data and resources}

All the accelerometric data are part of an unpublished dataset (property of ACEA-ATO2 S.p.A.).

Acknowledgments The Authors wish to thank Dario Rinaldis and Carlo Romagnoli for the scientific discussions on the findings. Thanks also to ACEA-ATO2 S.p.A. for the technical support. The research was carried on in the frame of: (1) Convention between CERI and ACEA-ATO2 S.p.A. for the study of the gravitational processes affecting the Peschiera Spring slope, Project leader: Prof. Alberto Prestininzi; (2) CoOperation Agreement between ENEA and Research Centre for Geological Risks (CERI) of the University of Rome (Italy) "Sapienza" on local seismic response research for seismic microzonation of sites of historicalmonumental value in Central Italy (Responsible: Prof. Gabriele Scarascia Mugnozza, Ing. Dario Rinaldis); (3) Co-operation Agreement between the Research Centre on Geological Risks CERI, of the University or Rome (Italy) "Sapienza," and the "French Institute for Sciences and Technology for Transport, Development and Networks" (IFSTTAR-Paris, France) on processing and analysis of seismic ground motions and analysis of possible relation between seismic records and local geological conditions (scientific coordinators: A. Prestininzi and J. Roudier).

Open Access This article is distributed under the terms of the Creative Commons Attribution License which permits any use, distribution, and reproduction in any medium, provided the original author(s) and the source are credited. 


\section{References}

Bigi S, Costa Pisani P (2002) Structural setting of the Cicolano-M. Calvo area (Central Apennines, Italy). Boll Soc Geol It Spec 1:141-149

Boni CF, Bono P, Capelli G (1986) Schema idrogeologico dell'Italia Centrale. Mem Soc Geol It 35:991-1012

Boni CF, Capelli G, Petitta M (1995) Carta idrogeologica dell'alta e media Valle del F. Velino. Elaborazione cartografica e stampa System Cart, Roma

Capotorti F, Fumanti F, Mariotti G (1995) Evoluzione tettonico-sedimentaria e strutturazione del settore di piattaforma carbonatica laziale-abruzzese nell'alta Valle del F. Velino. Studi Geol Camerti Spec 2:101-111

Casini S, Martino S, Petitta M, Prestininzi A (2006) A physical analogue model to analyse interactions between tensile stresses and dissolution in carbonate slopes. Hydrogeol J 14:1387-1402

Ciotoli G, Di Filippo M, Nisio S, Romagnoli C (2001) La Piana di S. Vittorino: dati preliminari sugli studi geologici, strutturali, geomorfologici, geofisici e geochimici. Mem Soc Geol It 56:297-308

Deparis J, Jongmans J, Cotton F, Bailler L, Thouvenot F, Hantz D (2008) Analysis of rock-fall and rock-fall avalanche seismograms in the French Alps. Bull Seism Soc Am 98(2):1781-1796

Eberhardt E, Stead D, Stimpson B, Read RS (1998) Identifying crack initiation and propagation thresholds in brittle rock. Can Geotech J 35:222-233

Evans S, Scarascia Mugnozza G, Strom A (2006) Landslides from massive rock slope failure. Nato Science Series, Springer, Netherlands. Series IV: Earth Environ Sci 49:662

Ganne P, Vervoort A, Wevers M (2007) Quantification of pre-peak brittle damage: correlation between acoustic emission and observed micro-fracturing. Int J Rock Mech Min Sci 44:720-729

Heng IS (2009) Rotating stellar core-collapse waveform decomposition: a principal component analysis approach. Class Quantum Grav 26:105005

Hildyard MW (2007) Manuel rocha medal recipient wave interaction with underground openings in fractured rock. Rock Mech Rock Eng 40:531-561

Hutchinson JN (1988) General report: morphological and geotechnical parameters of landslides in relation to geology and hydrogeology. In: Proceedings of 5th international symposium on landslides, Lausanne, Balkema, Rotterdam, pp 3-36

Joswig M (1990) Pattern recognition for earthquake detection. Bull Seism Soc Am 80:170-187

Joswig M (1994) Knowledge-based seismogram processing by mental images. IEEE Trans Syst Man Cybern 24(3):429-439

Lai XP, Cai MF, Xie MW (2006) In situ monitoring and analysis of rock mass behavior prior to collapse of the main transport roadway in Linglong Gold Mine, China. Int J Rock Mech Min Sci 43:640-646

Lei X, Masuda K, Nishizawa O, Jouniaux L, Liu L, Ma W, Satoh T, Kusunose K (2004) Detailed analysis of acoustic emission activity during catastrophic fracture of faults in rock. J Struct Geol 26:247-258

Maffei A, Martino S, Prestininzi A (2005) From the geological to the numerical model in the analysis of the gravity-induced slope deformations: an example from the Central Apennines (Italy). Eng Geol 78:215-236

Martino S, Prestininzi A, Scarascia Mugnozza G (2004) Geological-evolutionary model of a gravity-induced slope deformation in the carbonate central Apennines (Italy). Q J Eng Geol Hydrogeol 37(1):31-47

Miller A, Richards JA, McCann DM, Browitt CWA, Jackson PD (1989) Microseismic techniques for monitoring incipient hazardous collapse conditions above abandoned limestone mines. Q J Eng Geol Lond 22:1-18

Paskaleva I, Aronov AG, Seroglazov RR, Aronova TI (2006) Characteristic features of induced seismic processes in mining regions exemplified by the potassium salt deposits in Belarus and Bulgaria. Acta Geod Geoph Hung 41(3-4):293-303

Phillips WS, Pearson DC, Edwards CL, Stump BW (1997) Microseismicity induced by a controlled, mine collapse at white pine, Michigan. Int J Rock Mech Min Sci 34(314), paper 246

Savage WZ, Varnes DJ (1987) Mechanism of gravitational spreading of steep-sided ridges ("sackung"). Bull Int As Eng Geol 35:31-36

Szwedzicki T (2001) Geotechnical precursors to large-scale ground collapse in mines. Int J Rock Mech Min Sci 38:957-965

Szwedzicki T (2003) Rock mass behaviour prior to failure. Int J Rock Mech Min Sci 40:573-584

Tang C (1997) Numerical simulation of progressive failure and associated seismicity. Int J Rock Mech Min Sci 34(2):249-261

Walter M, Joswig M (2008) Seismic monitoring of fracture processes generated by a creeping landslide in the Vorarlberg Alps. First Break 26:131-135 
Walter M, Arnhardt C, Joswig M (2012) Seismic monitoring of rockfalls, slide quakes, and fissure development at the super-Sauze mudslide, French Alps. Eng Geol 128:12-22

Wust-Bloch GH, Joswig M (2006) Pre-collapse identification of sinkholes in unconsolidated media at Dead Sea area by "nanoseismometric monitoring" (graphical jackknife location of weak sources by few, low-SNR records). Geophys J Int 167:1220-1232

Yang X, Stump BW, Phillips WS (1998) Source mechanism of an explosively induced mine collapse. Bull Seismol Soc Am 88(3):843-854

Zischinsky U (1969) Uber Sackungen. Rock Mech 1:30-52 